\title{
Limitation and Difficulty Analysis of Quality Improvement Program Implementation in Urmia Small Industries
}

\author{
Fariba Azizzadeh ${ }^{1}$, Morad Shamsi ${ }^{1}$, Seidmehdi Veiseh ${ }^{2}$ \& Farideh Kamari ${ }^{3}$ \\ ${ }^{1}$ Department of management Esfahan, 'Science and Research Branch’, Islamic Azad University, Iran \\ ${ }^{2}$ Department of Humanities, Ilam University and PHD student Payame Noor University, Tehran, Iran \\ ${ }^{3}$ Instractor of Ilam education organization and student of M.A in educational technology, Kermanshah Azad \\ University, Iran \\ Corespondence: Fariba Azizzadeh, Department of management Esfahan, 'Science and Research Branch', Islamic \\ Azad University, Iran. Tel: 98-914-348-5482. E-mail: sazizzadeh2010@yahoo.com
}

Received: April 24, 2012

Accepted: June 1, 2012 Online Published: July 20, 2012

doi:10.5539/ibr.v5n8p190

URL: http://dx.doi.org/10.5539/ibr.v5n8p190

\begin{abstract}
According to nowadays competitive environment, quality improvement programs appear to be significant more than ever in order to achieve better production and services, costs reduction, and increasing the performance, quality improvement programs are implemented to increase the production and services quality in small industries, and because of their special features, establishing these programs are facing limitations. A lot of researches conducted either inside or outside the country survived the effective factors on quality improvement programs (inter-organizational and out-organizational factors), that we can refer to management support, training and organizational culture (inter-organizational factor), Society culture, static and dynamic environment, economical statue (out-organizational factors). The present research is aimed to survey the difficulty and quality improvement programs implementation problems in Urmia industrial estates, this study was analyzed on exams and statistical software basis. This research finding approves the relationship between technology, personnel and manager's attitude, proficiency and economical limitation with quality improvement programs, in other words, technology, personnel and managers attitude toward quality improvement programs are five factors which greatly influence the quality improvement programs establishment and in case of deficiency in these factors, they can be considered as quality improvement program's implementation barriers.
\end{abstract}

Keywords: quality improvement program, small industries, efficiency, industrial estate

\section{Introduction}

Certain product's or services Sellers and suppliers competition appears to in different forms, but quality is the most significant aspect (fatemi, Qomi, 1991), as well, quality is one of the most important factors which can play a significant role in obtaining required income and ultimately in the country (Mehregan, 2000). Quality planning consists of those activity categories which determine the goals and quality requirement and requirement relevant to the quality system component usage (Jamshidy, 2000). Companies are using various quality improving programs to increase their product or services production quality, although some times this programs implementation are facing problems and barriers, identifying these problems and them is the most important duty which organizations require it to achieve a continual quality improvement.

Small business are considered as an important strategy to decease the unemployment, these industries special character are as flexibility, creativeness behavior and quick decision making that are considered as it's benefits, and from these industrial defectiveness human and financial and information limitation could be referred (Akyüz, et al., 2006). Establishing quality improvement program in these require considering these features that could be relevant to the limitation, so in this research by considering special condition an situation of small industries, we tried to identify the problem and difficulty of quality improvement programs establishment.

\section{Research Significance}

By considering the intensive competition between certain product or service sellers and supplier in the recent years, production and services quality obliged most of the organizations to pay a lot of attention to quality improvement implementation, in this regard what is important is paying attention to the barrier and these 
programs establishment, and by considering that Urmia industrial estates, are from those industries which play a significant role in making job opportunity and industrial production of this city, it is obvious that intensive attitude of effective factors on quality improvement programs establishment in these industries, will play a key role in achieving organizational goals and also in increasing the productivity.

I this research we tried to survey inter-organizational variables (personnel and managers attitude, technology, proficiency and economical limits) on quality improvement program implementation in small industries in relation to these industrial special condition.

Various researches both domestic and foreign resource study the quality improvement programs showed that different researchers recognized various factors that are effective in this case. according to Mr. Noriaki, Kano, Paul lilrock point of view human inactivity, unwillingness in utilizing quality control approaches, resource loss, management system and society culture weakness are factors which influence quality improvement programs (Lilrock, Kano, 1985), while Ben clegg and boon tan believes that consumers needs and rival performance are the important factors in these programs implementation (Clegg \& Tan, 2007).

Main barriers, survived in Iran are as: economical barrier, consumer and personnel satisfaction, resources (financial and human), organizational culture and structure, educational barriers, expectations and attitudes (Jamshidi, 2000; Doniavy, 2004; Nemati, 2006).

\section{Research Review}

According to the conducted domestic and foreign researches, various factors are identified as effective factor on quality improvement programs implementation, in this case, (Torani, et al., 2008) survived management and supervisors inadequate commitment, inappropriate organizational structure in relation to the quality system, personnel low cooperation, not paying attention, personnel training and deficiency in organizational communication (Torani et al., 2008).

The most important effective factor on quality improvement programs are as managers support, continual training, and senior managers commitment and presenting strategic planning, and also in the following category, managers and personnel incomplete information is considered as the significant factor in the mentioned program failure (Hamidi \& Tabibi, 2004).

According to the results coming out of Vatankhah et al. (2010) research, organizational culture play a greatly influencing role in continual quality improving program implementation, the more the organizational culture enjoys the team culture characterization, the more implementation level and quality improvement program implementation will be, and the more hierarchy culture be stronger, the less success will come out in relation to the quality improving performance (Vatankhah et al., 2010). Nemati in his research concluded that there is a meaningful relationship between quality management systematic training, organizational culture, personnel expectation and anticipation and establishing these systems (Nemati, 2006). Kebriaei et al. in 2004 identified the consumers expectation and perception from services quality as an important factor on quality improvement program implementation (Kebriaei et al., 2004).

In other research conducted in west Azerbaijan province standard administration, quality control responsible capabilities, managers and executive organization cooperation with quality control responsible, financial and human resource facilities, trust to the control responsible capability, quality control custodian attitude, quality control responsible satisfaction, the country economical condition and lack of knowledge were introduced as an effective factors on the quality control system establishment (Doniavy, 2004).

In another research conducted in west Azerbaijan province food industry, manager's manufacturing unit's lack of proficiency, lack of expert's presence in manufacturing units, ownership and management oneness, lack of facilities and competition absence in producing stage as an effective factor on the examined quality management establishment. It is from these research findings that three groups of cumbersome evidence, strict structure and absence of control readiness were identified as the establishing and maintaining ISO 9000 quality system barriers (Jamshidi, 2000).

Fuentes-Fuentes et al. (2004) studied the environmental barriers and according to their results, static environment facing comprehensive quality management implementation with difficulties (Fuentes-Fuentes et al., 2004).

Other research results in this ground refer that trust absence in the environment influence the quality improvement programs (Zhao et al., 2004). 
Galperin likewise in surveying the environment, introduced the society culture an important factor, in population-oriented culture like Mexico implementing comprehensive quality management was more successful than individual-oriented culture like Canada. In fact he introduced individual-oriented culture as one of the comprehensive quality management barrier (Galperin et al., 1999). In a research conducted in china, South Korea and Taiwan, special cultural dimensions were considered as the influencing factors in quality management effectiveness, (Tomas \& Wacker, 2010). Vecchi and Brennan in their research concluded that countries more avoiding low distrust, the more they are committed to the compliance and conformance of high production quality, also they states that countries enjoys culture with low power gap, individualism and democracy, pay lower attention to their quality program implementation. (Vecchi \& Brennan, 2011)

In research conducted by Taveira et al., organizational work place environment (as senior manager's support) was introduced as an effective factor in resource quality management implementation (Taveira et al., 2003).

Simecurkovic and Robert sroufe believes that appropriate assessing tools absence is the quality program effectiveness barriers (Curkovic \& Sroufe, 2007).

In another research conducted in turkey industries, 32 factors which greatly influence the comprehensive quality management implementation were identified, that the most important mentioned one is the quality improvement and higher income, also this research results shows that if these factors go under control, will cause the comprehensive quality management establishment and will increase their success level (Bayazit \& Karpak, 2007).

Jayaram et al. 2010 in their research concluded that three structural factor as management commitment, focus on consumer and trust in comprehensive quality management success are very important (Jayaram et al., 2010). Also leadership competencies (Das et al., 2011), internal motivation (Prajogo, 2011), quality culture (Jinuhui et al., 2011), aggressive organizational culture (Morrow et al., 2011) and generally organizational culture (Irani \& Beskesi, love, 2004) are other factors which were studied by different researchers and their influence on successful management programs and quality guarantee implementation was approved.

\section{Some of the National Quality Model Awards}

\subsection{Malcom Baldrige National Quality Award}

Malcom baldrige was the United States trade minister on 1981-1987, he believes quality management key role as a means of long-term welfare and power of the country, he arranged activity on the ground of quality improvement that eventually led to pass an award which was named to honor him, this model was implemented in the united states and mainly consist of three groups:

First group: award for educational institution

Second group: award for business institution

Third group: award for healthcare institution

Malcom baldrige PLUSSAGE model consist of eleven concepts and basic principle that are as follow:

- leadership based on objectivity

- valuing the personnel and business partner

- excellence based on customer

- innovation management

- fact-based management

- individual and organizational learning

- focus on future

- alacrity

- social responsibility

- focus on results and value creation

- systematic attitude

Malcom baldrige model enjoys seven criteria which come out from the above eleven principles, in this model each criterion was divided to several sub-criteria to evaluate the organizations, these criteria are consisting of the following:

- leadership

- strategic planning

- focus on consumers and market 
- measuring, analyzing and knowledge management

- human resource concentration and development

- process management

- business results

Malcom baldrige model's criterion are presented in the below shape in a systematic approach.

Organizations, environment,

Communications, challenges face

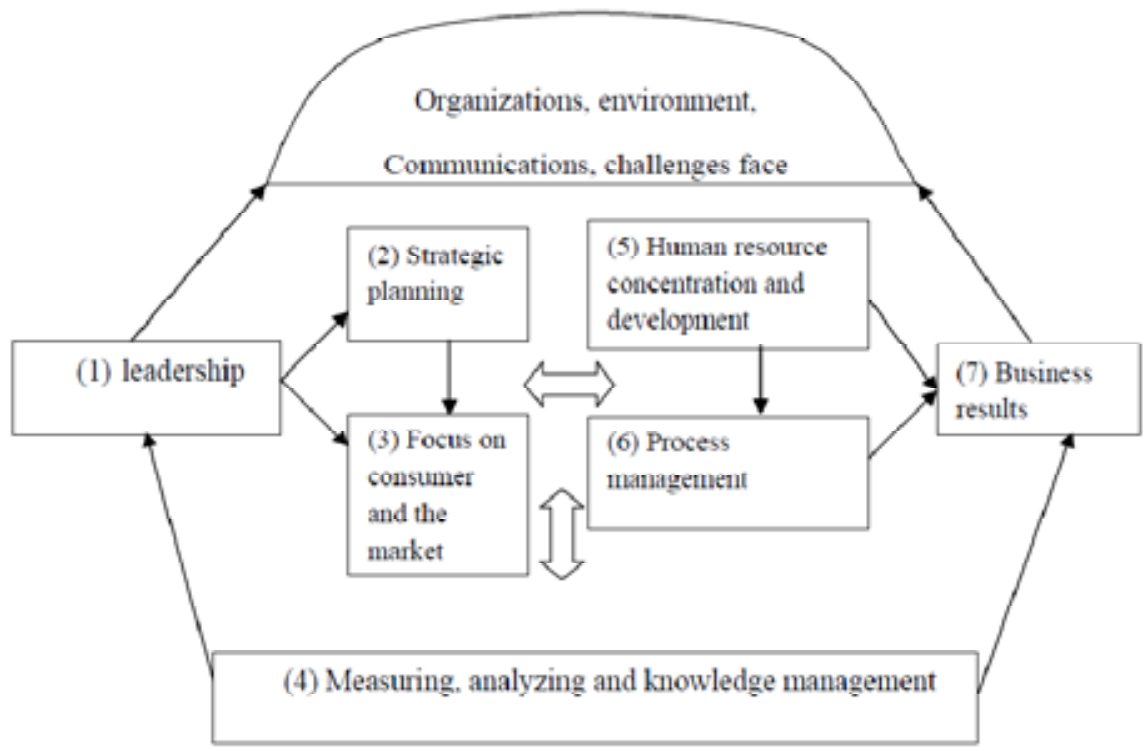

Figure 1. Malcom baldrige model’s with systematic approach (Asgharizadeh, Nasroallahi, 2007)

\subsection{Deming Quality Award Model}

Deming quality award model play a significant role in relation to quality control development and quality management. All the companies which received this award designed their quality control system very orderly and formed a special inspection group. This model is reviewed and revised frequently from its early design, now Deming quality award is divided into four categories:

- Deming award for individuals

- Deming functional award

- Deming application award for foreign companies

- Quality control award for operations business units

Deming model enjoys 56 features that all have the same weight in the model, each one of the features are divided to several criterion, that these sub-criterion are the basis of organizations assessing, Deming quality award criterion are as follow:

- Organization policy

- Training and manpower training (human resource training)

- Information collecting and usage methods

- Organizing approach and organization main activity

- Analysis method and the existing problem and difficulties survey

- Quality guarantee

- Results coming from quality control activity

- Activities control methods

- Activity Standardization methods

- Planning for the future

The mentioned criterions are the organizational assessing basis, that all have the same weight in the model, nowadays most of the countries relying on this model, establishing national and regional prizes that are 
organizational motivators toward excellence, growth and wealth making. In fact this pattern plays a significant role in organizations correct orientation. Simplified Deming model framework is illustrated in the following.

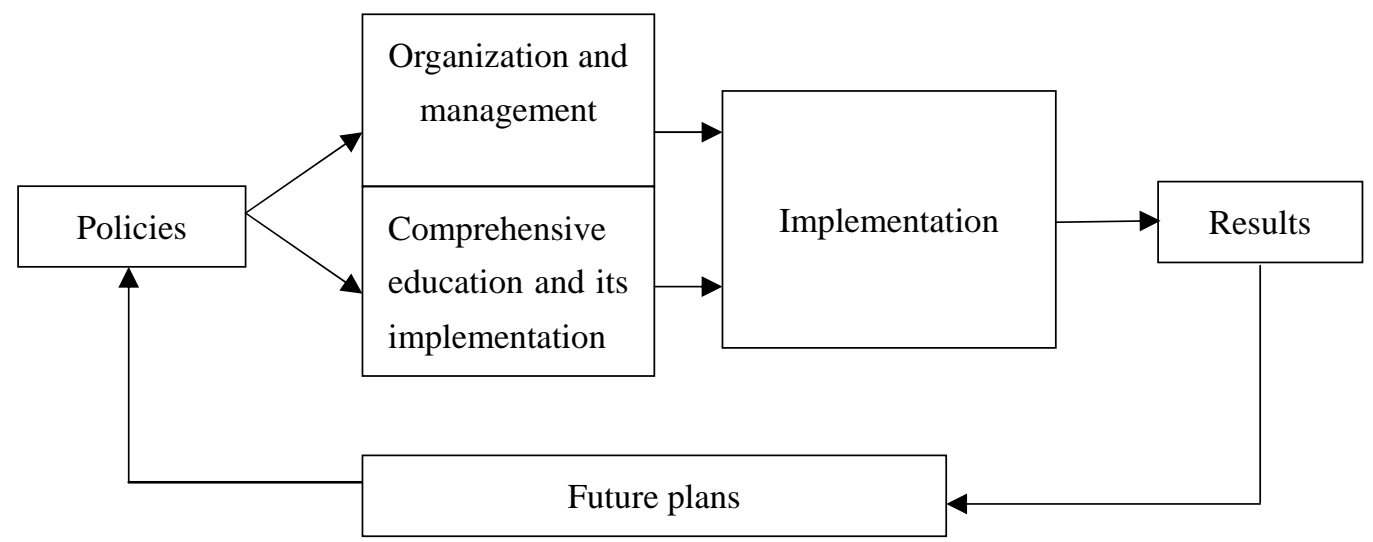

Figure 2. Simplified Deming model framework diagram (Asgharizadeh, Naroallahi, 2007)

\subsection{Process Costing Model}

This model was suggested by Crosby in 1979, which in fact identify the quality costs from qualitative activities. Qualitative activities consist of all the qualitative activities which are conducted in order to improve the production, services and processes:

Crosby divided qualitative activities into two categories:

1- Categories which are conducted for the first time, that production, services and processes level of quality reaches the desired qualitative level.

2- Activities conducted to fixing deficiency, reworking and etc. after achieving weak qualitative level in order to improve. Crosby calls costs coming out of the first class as compliance costs and costs coming out of second class activity as non-compliance costs. (Emamy, 2007)

\section{Research Method}

This survey if applicable research and is conducted on survey approach basis, in this method we tried to evaluate individual empirical attitude in order to realize the quality improving programs implementation difficulties and limits on the Urmia industrial estates level from managers and personnel's perspectives.

The surveyed society consist of all the factories located in Urmia industrial estates, according to the statistical reports about 8600 persons are working in these industrial estates, the sampling was carried out by using Cochran formula and led to sample density equal to 240 persons of personnel and managers which were selected in accidental method. To collect the data a questionnaires consist of 30 questions were used, which survived the quality improvement programs different aspects. Also the answer domain was classified on basis of likert classification from very high to very low, for questionnaires durability and data analysis we used the statistical techniques and software's.

\section{Goals, Hypotheses and Central Research Question}

By thematic and theoretic literature review, this research aim is to survey the internal variables situation (technology, manager's attitude, managers proficiency level, economical limits and personnel attitude) and also these variables effect on quality improving programs implementation. We offered thesis to reach to these goals:

Hypothesis 1: There is a meaningful relationship between technologies are used in small industries and quality improving programs development absence.

Hypothesis 2: There is a meaningful relationship between quality improving programs and quality improving programs developments absence.

Hypothesis 3: There is a meaningful relationship between manager's proficiency and quality improving programs developments absence.

Hypothesis 4: There is a meaningful relationship between small industries economical limits and quality improving programs developments absence. 
Hypothesis 5: There is a meaningful relationship between personnel attitude toward quality improving programs and quality improving programs developments absence.

This research questions were divided in two categories, the first one is evaluating inter-organizational issues and the other is evaluating out-organizational issues.

Questions which evaluates the utilized technology level in small industries, rotates around the machinery and equipment axis, planning, ISO, competition among companies and quality control, also central questions which evaluate manager's attitude theory to the quality improving programs are on the ground of cooperation and consultation interest, quality improving programs effect, pseudo-income ground and quality culture, to test the manager's proficiency theory, question's as manager's knowledge and awareness, employing experts, planning, proficiency level, employing experts and the utilized professional training level were used. Attitude survey question evaluate the interest-rate, intermediary and broker, official and non-official institution financial support, relevant production unit financial facilities, panning and competitive market absence, the theory evaluate the economical limits of small industries. And finally, questions like personnel willingness, personnel and manager's cooperation and consultation, people purchase potential, abundance of Chinese goods, and job safety low level, evaluate personnel attitude toward the quality improving programs.

\section{Research Conceptual Model}

In information era special features leads the world, that change speed is the most important one, that each moment adds to it's acceleration, in this environmental condition, an economical institute or service institute can reach to it's organizational goals and improve it's productivity in the organization when it recognize this changes, predict them and finally accept them and keep pace with them. So what we must evaluate on this ground is that according to the changes and evolutions in the technology and massive competition, does the technologies are used in Urmia small industries are enough effective to implement quality improve program? By considering that manager's negative attitude toward quality improving programs which are the main supporter of these programs, face these programs with barriers, so it is capable to be evaluated.

And also quality control managers and responsible are those who play an effective role in quality improve program, so their proficiency level on this ground can be determining factor and thus have the capability to be studied.

Regarding that small industries are grappling with financial limits (Akyüz et al., 2006), it leads to the information and human limits. So small industries economical barriers can be one of the factors which influence these programs implementation, and also personnel are the main executive of these quality improving programs, and if there is adequate motivation absence on this ground, it can be one of the important factors which facing this program with problems.

In relation to the discussed introduction, the utilized technology factors in small industries, manager's attitude, quality control responsible level of proficiency, economical limits and personnel were chosen as attitude as effective variables, the conceptual model of this research is as follow:

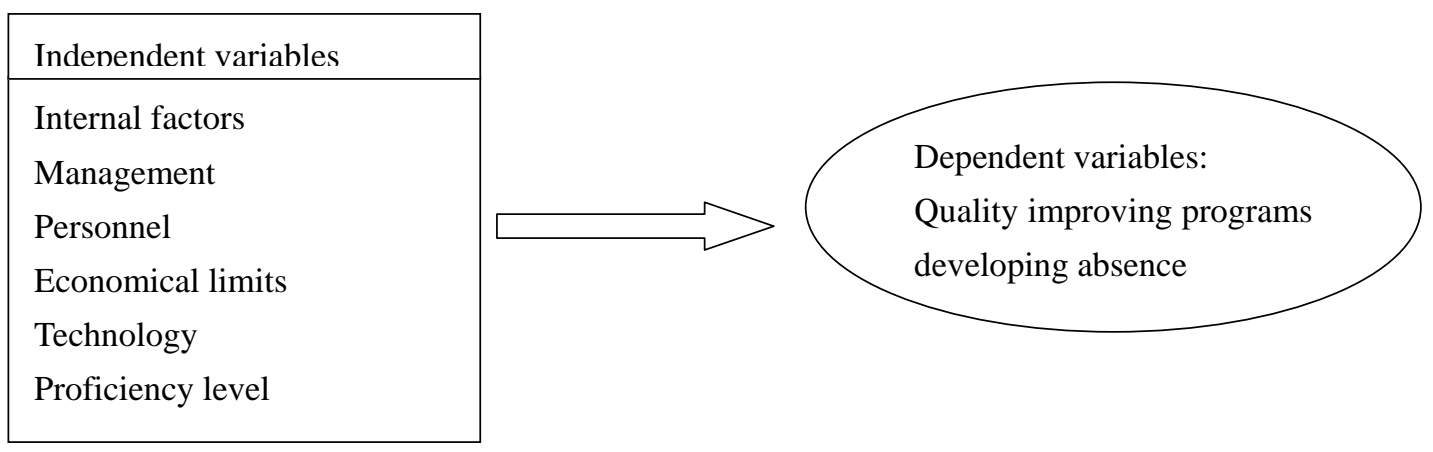

Figure 3. Dependant and independent variable relationship

\section{Research Findings}

This research finding are revealing that total score average on the ground of technology are (80/71) with standard deviation 29/91. According to the obtained results, it seems that there is a meaningful relation between the 
technologies utilized in small industries and quality improvement program implementation with $5 \%$ error level $(\mathrm{p}=.000<.05)$. So we can not reject the above theory.

Manager's Proficiency level on quality improve programs total score average (66/47) are accompanied with 25/706 standard deviation. According to the obtained results we saw a meaningful relation between manager's proficiencylevels and quality improving programs are accompanied with.05 error level $(p=.000<.05)$. So the above theory will be accepted.

Small industries total score average (63/19) accompanied with 21/985 standard deviation 21/985, the obtained information reveals that there is a meaningful relation between small business economical limits and quality improve programs development absence with $5 \%$ error level $(\mathrm{p}=.000<.05)$. So this theory will be accepted.

Personnel attitude toward quality improving programs total score average (64/96) accompanied with standard deviation 23/84, the obtained results shows that there is a meaningful relation between personnel attitude toward quality improving programsand developing these programs with .05 error level $(p=.000<.05)$ so this can't be rejected, either.

Table 1. Research obtained results

\begin{tabular}{ccccc}
\hline Research theories & Average & Standard deviation & p-value & Xi-d \\
\hline Theory 1 & $80 / 71$ & $29 / 91$ & $0 / 000$ & $193 / 708$ \\
Theory 2 & $67 / 16$ & $23 / 049$ & $0 / 000$ & $46 / 011$ \\
Theory 3 & $66 / 47$ & $25 / 706$ & $0 / 000$ & $102 / 317$ \\
Theory 4 & $63 / 19$ & $21 / 985$ & $0 / 000$ & $177 / 487$ \\
Theory 5 & $64 / 96$ & $23 / 84$ & $0 / 000$ & $125 / 477$ \\
\hline
\end{tabular}

\section{Conclusion and Suggestions}

This present research was conducted aimed to analyze quality improving programs implementation problems and limits in Urmia small industries that the studied society consists of industrial estate.

According to the experts point of view, personnel internal motivation is a significant factors in quality improving programs implementation (Irani \& beskee, 2004), that by analyzing these research results it appears that Personnel attitude toward quality improving programs play a significant role in these programs implementation, this means that in case of negative Attitude of personnel's toward the quality improving programs, these programs establishment in the organizations will encounterproblems. So as a result, training plans are essential for increasing personnel motivation in order to implement quality improvement programs.

Other researchers introduce motivation, manager's support and commitment to play a significant role in quality improving programs (Torani, Tabibi, Shahbazi, 2008; Hamidi, Tabibi, 2003; Doniavy, 2003; Jarayem et al., 2010), according to this research results likewise manager's attitude toward the quality improving programs is another key factor that play a significant role. Manager's negative attitudes toward these programs encounter their establishment with difficulty which is recommended to apply the essential training to increase the manager's motivation.

According to the researcher's findings training and increasing the information is the most important thing to do which is needed to success in quality improving programs. (Hamidi, Tabibi, 2003; Nemati, 2004). According to the obtained results from this research, manager's and quality control responsible proficiency level is of those factors that if this factor level is low, consider as this programs implementation barriers. So it is recommended to increase managers and quality control responsible proficiency level in relation to the relevant training.

A study conducted on 1999-2000 in turkey manufacturing industry. That consists of 851 small and medium industrial company of this country, the results shows that budget barriers greatly influence small company performance. (Akyüz et al., 2006), and also other research introduce economical difficulties as significant barrier (Doniavy, 2003), according to the present research results there is a relationship between small industrial limits and quality improvement programs development absence. So, increasing small business economical potential is recommended in company with training in order to achieve quality improvement programs implementation.

In the present research it was determined that updating machinery and equipment and generally technology's utilized on the ground of quality improvement is an effective factor which by planning on this ground we can achieve success in establishing this program, and also on this ground conducting comparative studies with other countries which experienced successful quality improving implementation is from recommended solutions. 


\section{References}

Akyüz, K. C., Akyüz, I., Serin, H., \& Cindik, H. (2006). The financing preferences and capital structure of micro, small and medium sized firm ownersin forest products industry in turkey. Forest Policy and Economics, 8, 301-311. http://dx.doi.org/10.1016/j.forpol.2004.09.003

Amami, R. (2007). Quality costingmethods, Tadbirmagazine, Year eighteenth, No. 181, PP.124-136.

Asgharzadeh, E., \& Nasrollahi, M. (2007). Ranking companies based on the model of efficiency measures method PROMETHEE. Journal of Humanities, 11(3), 73-91.

Bayazit, O., \& Karpak, B. (2007). An analytical network process- based framework for successful total guality management (TQM): An assessment of Turkish manufacturing industry readiness. International Journal of Production Economics, 105, 79-96. http://dx.doi.org/10.1016/j.ijpe.2005.12.009

Clegg, B., \& Tan, B. (2007). Using QFD for e-business planning and analysis in a micro-sized enterprise. International Journal of Quality \& Reliability Management, 24(8), 813-828. http://dx.doi.org/10.1108/02656710710817108

Curkovic, S., \& Sroufe, R. (2007). Total Quality Environmental Management and Total Cost Assessment: An exploratory study. International Journal of Production Economics, 105, 560-579. http://dx.doi.org/10.1016/j.ijpe.2006.04.021

Das, A., Kumar, V., \& Kumar, U. (2011). The role of leadership competencies for implementing TQM. International Journal of Quality \& Reliability Management, 2, $195-219$. http://dx.doi.org/10.1108/02656711111101755

Doniavi, A. (2004). Systems analysis, quality control systems of major difficulty in production units under the Standards \& Industrial Research Office of West Azerbaijan province. research projects, Persian date Esfand 2004.

FatemiGhomi, M. T. (1999). Statistical quality control. Amirkabir University (Tehran Polytechnic), Winter 1999, first edition, p. 35.

Fuentes-Fuentes, M., Albacete-Sáez, C. A., \& Lloréns-Montes, F. J. (2004). The impact of environmental characteristics on TQM principles and organizational performance. Omega, 32, 425-442. http://dx.doi.org/10.1016/j.omega.2004.02.005

Galperin, B. L., \& Lituchy, T. R. (1999). The implementation of total quality management in Canada and Mexico: a case study. International Business Review, 8, 323-349. http://dx.doi.org/10.1016/S0969-5931(99)00006-2

Hamidi, Y., \& Tabibi. (2004). The results review of TQM implementation in Province healthcare networks 81-79. Scientific Journal of Hamadan University of Medical Sciences and Health Services, 1(31), 37-43.

Irani, Z., Beskese, A., \& Love, P. E. D. (2004). Total quality management and corporate culture: constructs of organizational excellence. Technovation, 24(8), 643-650. http://dx.doi.org/10.1016/S0166-4972(02)00128-1

Jamshidi, M. H. (2000). Review and identify the factors of quality management in West Azarbaijan province’s food industry (Public administration master's thesis).

Jayaram, J., Ahire, S. L., \& Dreyfus, P. (2010). Contingency relationships of firm size, TOM duration, unionization, and industry context on TQM implementation-A focus on total effects. Journal of Operations Management, 28, 345-356. http://dx.doi.org/10.1016/j.jom.2009.11.009

Kebriaei, A., Akbari, F., Hosseini, S. M., Eftekhar Ardebili, H., \& Pourreza, A. (2004). Survey on quality gap in primary health care in Kashan health centers. The Journal of Qazvin Univ. of Med. Sci., 31-53.

Kull, T. J., \& Wacker, J. (2010). Quality management effectiveness in Asia: The influence of culture. Journal of Operations Management, 28, 223-239. http://dx.doi.org/10.1016/j.jom.2009.11.003

Mehregan, M. R. (2000). Mathematical Behavior Motivation. Quality Management Journal, 49, 24-12.

Morrow, P. C., McElroy, J. C., \& Scheibe, K. P. (2011). Work unit incivility, job satisfaction, and total quality management among transportation employee. Transportation Research Part E, 1-11.

Nemati, L. L. (2006). Review the quality management system in Telecom West Azarbaijan province (public administration master's thesis MA). 
Prajogo, D. I. (2011). The roles of firms motives in affecting the outcomes of ISO 9000 adoption. International $\begin{array}{llll}\text { Journal of Operationa \& Production Management, } & \text { 1, }\end{array}$ http://dx.doi.org/10.1108/01443571111098753

Taveira, A. D., James, C. A., Karsh, B. T., \& Sainfort, F. (2003). Quality management and the work environment: an empirical investigation in a public sector organization. Applied Ergonomics, 34, 281-291. http://dx.doi.org/10.1016/S0003-6870(03)00054-1

Turani, S., Taybi, S. J., \& Shahbazi, B. (2008). Factors affecting the implementation of TQM in the educational hospitals of Iran University of Medical Sciences. Hakim Research Journal, Volume, 11(2), 22-32.

Vatankhah, S., Gohari, M. R., \& Abdi, J. (2010). Improve the quality of the relationship between organizational culture and development in selected Tehran University Medical Sciences hospitals. Institute of Health Sciences University Jihad monitoring Quarterly, Spring 2010, 189-195.

Vecchi, A., \& Brennan, L. (2011). Quality management: a cross-cultural perspective based on the GLOBE framework. International Journal of Operations\& Production Management, 5, 527-553. http://dx.doi.org/10.1108/01443571111126319

Wu, J. S., Zhang, D., \& Schroeder, R. G. (2011). Customization of quality practices: the impact of uality culture. International Journal of Quality \& Reliability Management, 3, 263-279. http://dx.doi.org/10.1108/02656711111109883

Zhao, X., Yeung, A. C. L., \& Lee, T. S. (2004). Quality management and organizational context in selected service industries of China. Journal of operations management, 22, 575-587. http://dx.doi.org/10.1016/j.jom.2004.08.003 